\title{
Call \& Put Butterfly Spreads Test of SET50 Index Options Market Efficiency and SET50 Index Options Contract Adjustment
}

\author{
Woradee Jongadsayakul
}

\begin{abstract}
This paper tests the efficiency of SET50 Index Options market and investigates the impact of contract adjustment on market efficiency. The options data set I employ to conduct call \& put butterfly spreads test of market efficiency covers the period from October 29, 2007 to December 30, 2016. When I ignore transaction costs, the results report frequent and substantial violations of pricing relationships. For an option maturing within 90 days, size of violations tends to be higher for options farther from the money or further away from expiration. Almost no violations remain after considering the bid-ask spread as transaction costs. Therefore, our results support the efficiency of SET50 Index Options market before and after the modification of contract specification. Comparing the results before and after contract adjustment, I do not observe any improvement of market efficiency after the modification of contract.
\end{abstract}

Index Terms-Butterfly spread, index options, market efficiency, no arbitrage condition.

\section{INTRODUCTION}

Thailand Futures Exchange (TFEX) was established on May 17, 2004 as a derivatives exchange in Thailand. It offers derivatives products such as futures and options to investors, fund managers, financial institution and the general public as tools to manage their portfolio effectively. The first product to be traded on TFEX is SET50 Index Futures, which was launched on April 28, 2006. TFEX has offered several products such as SET50 index options, gold futures, silver futures, interest rate futures, single stock futures, crude oil futures, USD futures, sector futures, and rubber futures since then. Although SET 50 Index Options has been traded since October 29, 2007 as the second product on TFEX, it has faced the liquidity problem. To increase liquidity in SET50 index options, TFEX added two contract months but removed the two farthest quarterly months, resulting in four contract months available for trading each day. In addition, strike price interval of SET50 Index Options has been increased from 10 points to 25 points, so that SET50 Index Options have 2 in-the-money, 1 at-the-money, and 2 out-of-money. The adjustment reduces the number of contracts and complexity involved and should boost trading liquidity and volume. It is observed that yearly volume of SET50 Index Options has continued to increase since 2012; however, it was just 0.62 percent of the total volume in 2016. Since the liquidity of SET50 Index Options depends on its pricing

Manuscript received March 23, 2018; revised June 6, 2018. This work was supported in part by Department of Economics, Kasetsart University.

Woradee Jongadsayakul is with Kasetsart University, Bangkok, Thailand (e-mail: fecowdj@ku.ac.th). efficiency, this paper conducts a call \& put butterfly spreads test over the sample period from October 29, 2007 to December 30, 2016 to analyze SET50 Index Options market efficiency before and after the contract adjustment. I focus on no-arbitrage relationships among prices to testing market efficiency since it does not rely on assumptions about traders' risk preferences and market price dynamics [1]. The call \& put butterfly spreads test also involves only options.

Some earlier studies report evidence of mispricing of SET50 Index Options when ignoring transaction costs. However, after including transaction costs, very few violations of arbitrage pricing relationships are reported. Research by [2] uses daily data from October 29, 2012 to October 30, 2014 to examine riskless arbitrage opportunity under put-call-futures parity. After including all transaction costs, such as the bid-ask spread and brokerage commission, a number of riskless arbitrage opportunities reduce significantly as $1 \%$ of total available data. Reference [3] provides the box spread test of SET50 index options market efficiency using daily data from October 29, 2012, through March 30, 2016. The box spread arbitrage strategy is appropriate for testing the SET50 index options market efficiency when SET50 index is not traded because the strategy involves only the risk free asset and two pairs of call and put options having the same expiration date and underlying asset, but not underlying asset itself. The results show that the market frictions imposed by the bid-ask spread, along with brokerage commissions, exchange fees, and interest on initial margin deposit, appear to have a significant effect on arbitrageurs' abilities to take advantage of the mispricing of the box spreads. The box spread arbitrage opportunities drop to less than $1 \%$ when using bid-ask prices, and none of them is persisted on the following trading day. Over the same sample period from October 29, 2012, through March 30, 2016, [4] and [5] use the internal efficiency test of call options alone or put options alone to investigate the existence of arbitrage opportunities in SET50 Index Options market. Using the bid-ask prices as transaction costs, there is no arbitrage opportunity for call options trading. The arbitrageurs can earn riskless profits when employing put butterfly spread, but their opportunities drop to $0.04 \%$ [4], [5]. There is only $0.01 \%$ for put spread arbitrage opportunities [5]. In addition to providing new results on the efficiency test of the SET50 Index Options market, this paper extends the sample period to cover both before and after the SET50 Index Options contract adjustment. I investigate whether SET50 Index Options are priced correctly relative to one another for the two sample periods, before and after the contract adjustment, by testing both call \& put butterfly spreads 
together. A group of previous studied conduct market efficiency test by using no-arbitrage approach, including call $\&$ put lower boundary conditions (e.g., [1], [6]), put-call parity condition (e.g., [1], [7]-[9]), call \& put spread conditions (e.g., [1], [10], [11]), call \& put convexity conditions (e.g., [1], [10], [11]), and box spread condition (e.g., [1], [10]-[12]). However, as of my knowledge, this is the first paper combining both call and put butterfly spreads to test market efficiency.

The paper proceeds as follows. A brief review of theoretical framework is given in Section II. The description of the data and a discussion of the testing methodology follow in Section III. The test results are presented in section IV, and Section V concludes.

\section{THEORETICAL FRAMEWORK}

The condition of call \& put butterfly spreads involves call and put options characterized by 1$)$ three different exercise prices, $\left.K_{1}<K_{2}=\left(K_{1}+K_{3}\right) / 2<K_{3} ; 2\right)$ the same underlying asset; and 3) the same expiration date. Define $C_{i}$ and $P_{i}$, the premium of European call and put options with exercise price $K_{i} ; S$, the price of underlying asset; $r$, the risk-free rate; $t$, years remaining until option expiry. Based on the put-call parity by [13], options pricing relationships are as follows:

$$
\begin{aligned}
& C_{1}=P_{1}+S-K_{1} e^{-r t} \\
& C_{2}=P_{2}+S-K_{2} e^{-r t} \\
& C_{3}=P_{3}+S-K_{3} e^{-r t}
\end{aligned}
$$

Subtracting twice (2) from the sum of (1) and (3), I have

$$
C_{1}+C_{3}-2 C_{2}=P_{1}+P_{3}-2 P_{2}-\left(K_{1}+K_{3}-2 K_{2}\right) e^{-r t}
$$

If $K_{1}<K_{2}=\left(K_{1}+K_{3}\right) / 2<K_{3}$, then $K_{1}+K_{3}-2 K_{2}=0$. The condition of call $\&$ put butterfly spreads used in this paper is then as follows:

$$
C_{1}+C_{3}-2 C_{2}=P_{1}+P_{3}-2 P_{2}
$$

If (4) is violated, arbitrage profits can be generated by employing the following strategies.

\section{A. Long Call Butterfly Spread and Short Put Butterfly Spread (LCSP) Strategy}

If the left-hand side of (4) is less than the right-hand side of (4), an arbitrager can earn risk-free profit by combining long call butterfly spread and short put butterfly spread. A long call butterfly spread is a combination of a bull call spread (purchase of a call with exercise price $K_{1}$ and sale of a call with exercise price $K_{2}$ ) and a bear call spread (sale of a call with exercise price $K_{2}$ and purchase of a call with exercise price $K_{3}$ ). A short put butterfly spread is a combination of a bear put spread (sale of a put with exercise price $K_{1}$ and purchase of a put with exercise price $K_{2}$ ) and a bull put spread (purchase of a put with exercise price $K_{2}$ and sale of a put with exercise price $K_{3}$ ). The LCSP strategy involves a positive initial inflow, $2 C_{2}-C_{1}-C_{3}+P_{1}+P_{3}-2 P_{2}$, and zero payoff at expiration (see Table I).

\section{B. Short Call Butterfly Spread and Long Put Butterfly Spread (SCLP) Strategy}

If the left-hand side of (4) is greater than the right-hand side of (4), an arbitrager can earn risk-free profit by combining short call butterfly spread and long put butterfly spread. A short call butterfly spread is a combination of a bear call spread (sale of a call with exercise price $K_{1}$ and purchase of a call with exercise price $K_{2}$ ) and a bull call spread (purchase of a call with exercise price $K_{2}$ and sale of a call with exercise price $K_{3}$ ). A long put butterfly spread is a combination of a bull put spread (purchase of a put with exercise price $K_{1}$ and sale of a put with exercise price $K_{2}$ ) and a bear put spread (sale of a put with exercise price $K_{2}$ and purchase of a put with exercise price $K_{3}$ ). The SCLP strategy involves a positive initial inflow, $C_{1}+C_{3}-2 C_{2}-P_{1}-P_{3}+2 P_{2}$, and zero payoff at expiration

\begin{tabular}{|c|c|c|c|c|c|c|c|}
\hline $\begin{array}{l}\text { Price Range at } \\
\text { Expiration } T\end{array}$ & $\begin{array}{l}\text { Payoff from Short } \\
1 \text { Call with } K_{1}\end{array}$ & $\begin{array}{l}\text { Payoff from Long } \\
2 \text { Calls with } K_{2}\end{array}$ & $\begin{array}{l}\text { Payoff from Short } \\
1 \text { Call with } K_{3}\end{array}$ & $\begin{array}{l}\text { Payoff from Long } \\
1 \text { Put with } K_{1}\end{array}$ & $\begin{array}{l}\text { Payoff from Short } \\
2 \text { Puts with } K_{2}\end{array}$ & $\begin{array}{c}\text { Payoff from Long } \\
1 \text { Put with } K_{3}\end{array}$ & $\begin{array}{l}\text { Total } \\
\text { Payoff }\end{array}$ \\
\hline$S_{T} \leq K_{1}$ & - & - & - & $K_{1}-S_{T}$ & $-2\left(K_{2}-S_{T}\right)$ & $K_{3}-S_{T}$ & 0 \\
\hline$K_{1}<S_{T} \leq K_{2}$ & $-\left(S_{T}-K_{1}\right)$ & - & - & - & $-2\left(K_{2}-S_{T}\right)$ & $K_{3}-S_{T}$ & 0 \\
\hline$K_{2}<S_{T} \leq K_{3}$ & $-\left(S_{T}-K_{1}\right)$ & $2\left(S_{T}-K_{2}\right)$ & - & - & - & $K_{3}-S_{T}$ & 0 \\
\hline$K_{3}<S_{T}$ & $-\left(S_{T}-K_{1}\right)$ & $2\left(S_{T}-K_{2}\right)$ & $-\left(S_{T}-K_{3}\right)$ & - & - & - & 0 \\
\hline
\end{tabular}
(see Table II).

TABLE I: PAYOFFS FROM THE LCSP STRATEGY

\begin{tabular}{cccccccc}
\hline \hline $\begin{array}{c}\text { Price Range at } \\
\text { Expiration } T\end{array}$ & $\begin{array}{c}\text { Payoff from Long } \\
\text { 1 Call with } K_{1}\end{array}$ & $\begin{array}{c}\text { Payoff from Short } \\
\text { 2 Calls with } K_{2}\end{array}$ & $\begin{array}{c}\text { Payoff from Long } \\
\text { 1 Call with } K_{3}\end{array}$ & $\begin{array}{c}\text { Payoff from Short Payoff from Long } \\
1 \text { Put with } K_{1}\end{array}$ & $\begin{array}{c}\text { Payoff from Short } \\
\text { 2 Puts with } K_{2}\end{array}$ & $\begin{array}{c}\text { Total Put with } K_{3} \\
\text { Payoff }\end{array}$ \\
\hline$S_{T} \leq K_{1}$ & - & - & - & $-\left(K_{1}-S_{T}\right)$ & $2\left(K_{2}-S_{T}\right)$ & $-\left(K_{3}-S_{T}\right)$ & 0 \\
$K_{1}<S_{T} \leq K_{2}$ & $S_{T}-K_{1}$ & - & - & - & $2\left(K_{2}-S_{T}\right)$ & $-\left(K_{3}-S_{T}\right)$ & 0 \\
$K_{2}<S_{T} \leq K_{3}$ & $S_{T}-K_{1}$ & $-2\left(S_{T}-K_{2}\right)$ & - & - & - & $-\left(K_{3}-S_{T}\right)$ & 0 \\
$K_{3}<S_{T}$ & $S_{T}-K_{1}$ & $-2\left(S_{T}-K_{2}\right)$ & $S_{T}-K_{3}$ & - & - & - & 0 \\
\hline \hline
\end{tabular}

TABLE II: PAYOFFS FROM THE SCLP STRATEGY 


\section{DATA Methodology}

Options on the SET50 has been traded on the TFEX since October 29, 2007. They are European-style options. As is usual for index options, prices of SET50 Index options are in index points. The contract size is 200 baht per index point. The options data set I employ to test call \& put butterfly spreads consists of closing prices, bid prices, and ask prices in the period from October 29, 2007 to December 30, 2016 for a total of 10,629 observations. To study how the contract modification affects the efficiency of the SET50 Index Options market, I spilt a given data set into 2 periods, before and after contract adjustment on October 29, 2012. The market efficiency tests were carried out under the assumption of both zero and positive transaction costs. Closing prices $(C L)$ are used under the assumption of zero transaction costs. With the bid-ask spread as transaction costs, an option can be purchased at the ask price $(A)$ and sold at the bid price $(B)$. Under two assumptions, without and with transaction costs, Table III and Table IV show the arbitrage conditions of the LCSP strategy and the SCLP strategy, respectively. The arbitrage conditions must be multiplied by 200 to express in terms of baht instead of index point. When the arbitrage opportunities are detected, the comparison of the size of arbitrage profits $(Y)$ in SET50 Index Options pricing relationships before and after change in contract specification on October 29, 2012 is analyzed by using t-test at significance level of 5 percent.

TABLE III: ARBITRAGE CONDITIONS OF THE LCSP STRATEGY

Assumption Arbitrage Condition

\begin{tabular}{lc}
\hline Without & Arbitrage Condition \\
transaction costs & $Y=\left(2 C_{2}^{C L}-C_{1}^{C L}-C_{3}^{C L}+P_{1}^{C L}+P_{3}^{C L}-2 P_{2}^{C L}\right) \times 200>0$ \\
With transaction & $Y=\left(2 C_{2}^{B}-C_{1}^{A}-C_{3}^{A}+P_{1}^{B}+P_{3}^{B}-2 P_{2}^{A}\right) \times 200>0$ \\
costs &
\end{tabular}

TABLE IV: ARBITRAGE CONDITIONS OF THE SCLP STRATEGY

\begin{tabular}{lc}
\hline \hline \multicolumn{1}{c}{ Assumption } & Arbitrage Condition \\
\hline Without & $Y=\left(C_{1}^{C L}+C_{3}^{C L}-2 C_{2}^{C L}-P_{1}^{C L}-P_{3}^{C L}+2 P_{2}^{C L}\right) \times 200>0$ \\
transaction costs & \\
With transaction & $Y=\left(C_{1}^{B}+C_{3}^{B}-2 C_{2}^{A}-P_{1}^{A}-P_{3}^{A}+2 P_{2}^{B}\right) \times 200>0$ \\
costs & \\
\hline \hline
\end{tabular}

\section{Test Results}

On each trading day during the test period, the arbitrage conditions of the LCSP strategy and the SCLP strategy are tested. The percentage and size of violations of the conditions are tabulated for the two sample periods, before and after the contract adjustment to indicate the effect of contract adjustment on SET50 Index Options market efficiency. Table $\mathrm{V}$ report the percentage and size of violations in arbitrage pricing relationship. I also investigate whether the baht value of violations decreases after the contract adjustment. To do so, I use a t-test of the null hypothesis that the mean baht violation is equal before and after contract adjustment.

In the absence of transaction costs, Table $\mathrm{V}$ shows a significant number of violations both before and after contract adjustment. Based on the whole sample of 10,629 observations, the total of 10,549 breaches of the condition of call \& put butterfly spreads is broken down into 5,303 (49.89\%) LCSP arbitrage opportunities and 5,246 (49.36\%) SCLP arbitrage opportunities. The average size of violations is 897.74 baht for the LCSP strategy and 889.81 baht for the
SCLP strategy. The percentage and baht amount of violations are higher in the later time period $(49.77 \%$ and 875.10 baht versus $50.16 \%$ and 946.65 baht) for the LCSP strategy. The t-test indicates the difference in size of the violations before and after contract adjustment at a significance level of $5 \%$. For the SCLP strategy, both measures decrease over time ( $49.41 \%$ and 892.10 baht versus $49.24 \%$ and 884.81 baht), though not significantly so. When the analysis considers the bid-ask spread as transaction costs, the percentage of violations drops substantially to less than $0.1 \%$. I also observe a decline in average size of violations to $396.67 \mathrm{baht}$ for the LCSP strategy and 40.00 baht for the SCLP strategy. The SET50 Index Options market is therefore efficient. Considering the LCSP strategy, the results show an insignificant increase in both percentage and baht amount of violations after contract adjustment $(0.03 \%$ and 80.00 baht versus $0.12 \%$ and 555.00 baht). There are no arbitrage opportunities for employing the SCLP strategy and generating arbitrage profits in a prior period contract adjustment. After contract adjustment, there are $0.06 \%$ of arbitrage opportunities in the SCLP strategy and an average arbitrage profit of 40.00 baht. The results do not provide support for the argument that the SET50 index options market efficiency improved after the modification of contract. In addition, the puts are usually overpriced relative to the calls so that the LCSP strategy is used more often and, in many cases, generates more arbitrage profits than the SCLP strategy before and after contract adjustment, regardless of the assumption of transaction costs.

TABLE V: Violations of CALl \& PUT ButTerfly SPREAdS

\begin{tabular}{lcccccc}
\hline \hline Transaction Costs & \multicolumn{3}{c}{ Zero } & \multicolumn{3}{c}{ Positive } \\
\hline Period & Before & After & Whole & Before & After & Whole \\
\hline Panel A: The LCSP strategy & & & & & \\
Number of Obs. & 7,284 & 3,345 & 10,629 & 7,284 & 3,345 & 10,629 \\
Number of Violations & 3,625 & 1,678 & 5,303 & 2 & 4 & 6 \\
Percent of Violations & 49.77 & 50.16 & 49.89 & 0.03 & 0.12 & 0.06 \\
Violation Size (baht) & 875.10 & 946.65 & 897.74 & 80.00 & 555.00 & 396.67 \\
T statistic (p-value) & $-2.4674(0.0137)$ & $-1.3030(0.2836)$ \\
\hline Panel B. The SCLP strategy & & & & & \\
Number of Obs. & 7,284 & 3,345 & 10,629 & 7,284 & 3,345 & 10,629 \\
Number of Violations & 3,599 & 1,647 & 5,246 & 0 & 2 & 2 \\
Percent of Violations & 49.41 & 49.24 & 49.36 & 0.00 & 0.06 & 0.02 \\
Violation Size (baht) & 892.10 & 884.81 & 889.81 & - & 40.00 & 40.00 \\
T statistic (p-value) & $0.2684(0.7884)$ & & - & \\
\hline \hline
\end{tabular}

Furthermore, to see if the violations are related to factors, such as option moneyness and time to maturity, previously cited in the literature (e.g., [7], [11]), arbitrage profits of the LCSP strategy and the SCLP strategy in the absence of transaction costs are classified by option moneyness $(M)$ and time to maturity $(t)$. The results are reported in Table VI for the LCSP strategy and Table VII for the SCLP strategy.

As there are three exercise prices $\left(K_{1}, K_{2}\right.$, and $\left.K_{3}\right)$, option moneyness is defined in (5) as the weighted average absolute percent difference between the three exercise prices and the daily closing price of SET50 Index $(S)$.

$$
M=\left(\left|S-K_{1}\right|+2\left|S-K_{2}\right|+\left|S-K_{3}\right|\right) \times 100 / 4 S
$$

For a total of 10,629 observations, there are 2,695 observations with moneyness less than $2 \%, 4,529$ observations with moneyness between $2 \%$ and $4 \%, 2,062$ observations with moneyness between $4 \%$ and $6 \%, 763$ 
observations with moneyness between $6 \%$ and $8 \%, 317$ observations with moneyness between $8 \%$ and $10 \%$, and 263 observations with moneyness greater than or equal to $10 \%$. Thus, the majority of observations are options being near the money.

TABLE VI: ARBITRAGE PROFITS OF THE LCSP STRATEGY BY OPTION MONEYNESS AND TIME TO MATURITY

\begin{tabular}{|c|c|c|c|c|c|c|}
\hline \multirow{2}{*}{$\begin{array}{c}\text { Period } \\
\text { Violation }\end{array}$} & \multicolumn{2}{|c|}{ Before } & \multicolumn{2}{|c|}{ After } & \multicolumn{2}{|c|}{ Whole } \\
\hline & $\%$ & baht & $\%$ & baht & $\%$ & baht \\
\hline \multicolumn{7}{|c|}{ Panel A: $t \leq 30$ days } \\
\hline$M<2 \%$ & 51.03 & 600.59 & 46.56 & 641.80 & 49.85 & 610.75 \\
\hline $2 \% \leq M<4 \%$ & 51.90 & 759.23 & 49.52 & 904.52 & 51.22 & 799.26 \\
\hline $4 \% \leq M<6 \%$ & 48.15 & 787.80 & 47.71 & $1,105.77$ & 47.99 & 903.43 \\
\hline $6 \% \leq M<8 \%$ & 53.10 & 862.67 & 57.95 & $1,026.27$ & 55.22 & 937.84 \\
\hline $8 \% \leq M<10 \%$ & 33.33 & 463.33 & 51.35 & $1,404.21$ & 42.47 & $1,040.00$ \\
\hline$M \geq 10 \%$ & 47.06 & $2,485.00$ & 59.46 & $2,701.82$ & 55.56 & $2,644.00$ \\
\hline \multicolumn{7}{|c|}{ Panel B: 30 days $<t \leq 90$ days } \\
\hline$M<2 \%$ & 50.95 & 737.02 & 48.03 & 612.51 & 50.12 & 703.31 \\
\hline $2 \% \leq M<4 \%$ & 48.66 & 892.98 & 50.98 & 821.37 & 49.43 & 868.35 \\
\hline $4 \% \leq M<6 \%$ & 46.28 & $1,107.25$ & 53.48 & $1,061.02$ & 48.33 & $1,092.66$ \\
\hline $6 \% \leq M<8 \%$ & 53.74 & $1,063.65$ & 46.67 & $1,071.07$ & 52.19 & $1,065.10$ \\
\hline $8 \% \leq M<10 \%$ & 42.86 & $1,210.95$ & 50.00 & $1,869.52$ & 44.12 & $1,342.67$ \\
\hline$M \geq 10 \%$ & 57.53 & $1,409.72$ & 60.87 & $2,108.57$ & 57.89 & $1,490.58$ \\
\hline \multicolumn{7}{|c|}{ Panel C: 90 days $<t$} \\
\hline$M<2 \%$ & 41.67 & 968.00 & 52.63 & $1,334.00$ & 51.14 & $1,293.33$ \\
\hline $2 \% \leq M<4 \%$ & 66.67 & 987.50 & 46.03 & $1,299.31$ & 47.83 & $1,261.52$ \\
\hline $4 \% \leq M<6 \%$ & 50.00 & 700.00 & 52.94 & $1,284.44$ & 52.63 & $1,226.00$ \\
\hline $6 \% \leq M<8 \%$ & 50.00 & $1,570.00$ & 40.00 & $1,180.00$ & 42.86 & $1,310.00$ \\
\hline $8 \% \leq M<10 \%$ & 100.00 & 780.00 & 50.00 & $1,020.00$ & 66.67 & 900.00 \\
\hline$M \geq 10 \%$ & - & - & - & - & - & - \\
\hline
\end{tabular}

TABLE VII: ARBITRAGE PROFITS OF THE SCLP STRATEGY BY OPTION MONEYNESS AND TIME TO MATURITY

\begin{tabular}{lcccccc}
\hline \multicolumn{1}{c}{ Period } & \multicolumn{2}{c}{ Before } & \multicolumn{2}{c}{ After } & \multicolumn{2}{c}{ Total } \\
\multicolumn{1}{c}{ Violation } & $\%$ & baht & $\%$ & baht & $\%$ & baht \\
\hline Panel A: $t \leq 30$ days & & & & & \\
$M<2 \%$ & 47.88 & 558.91 & 52.67 & 590.00 & 49.14 & 567.70 \\
$2 \% \leq M<4 \%$ & 47.72 & 725.41 & 50.24 & 847.30 & 48.44 & 761.43 \\
$4 \% \leq M<6 \%$ & 51.32 & 870.52 & 52.29 & $1,018.60$ & 51.68 & 925.32 \\
$6 \% \leq M<8 \%$ & 46.02 & 856.54 & 42.05 & $1,317.30$ & 44.28 & $1,048.09$ \\
$8 \% \leq M<10 \%$ & 66.67 & $1,253.33$ & 48.65 & $1,308.89$ & 57.53 & $1,277.14$ \\
$M \geq 10 \%$ & 52.94 & $1,324.44$ & 37.84 & $1,412.86$ & 42.59 & $1,378.26$ \\
\hline Panel B: 30 days $<t \leq 90$ days & & & & \\
$M<2 \%$ & 47.84 & 770.29 & 51.32 & 626.58 & 48.82 & 727.61 \\
$2 \% \leq M<4 \%$ & 50.36 & 933.16 & 48.41 & 773.08 & 49.71 & 881.16 \\
$4 \% \leq M<6 \%$ & 53.13 & $1,121.12$ & 45.77 & 970.87 & 51.03 & $1,082.67$ \\
$6 \% \leq M<8 \%$ & 45.56 & $1,110.15$ & 52.50 & $1,534.29$ & 47.08 & $1,213.72$ \\
$8 \% \leq M<10 \%$ & 56.12 & $1,092.55$ & 50.00 & $1,409.52$ & 55.04 & $1,143.36$ \\
$M \geq 10 \%$ & 41.94 & $1,345.13$ & 39.13 & $1,511.11$ & 41.63 & $1,362.30$ \\
\hline Panel C: 90 days $<$ & & & & & \\
$M<2 \%$ & 58.33 & 648.57 & 44.74 & 894.71 & 46.59 & 852.68 \\
$2 \% \leq M<4 \%$ & 33.33 & $1,445.00$ & 53.97 & $1,312.94$ & 52.17 & $1,320.28$ \\
$4 \% \leq M<6 \%$ & 50.00 & 420.00 & 45.10 & $1,513.04$ & 45.61 & $1,386.92$ \\
$6 \% \leq M<8 \%$ & 50.00 & 740.00 & 60.00 & 546.67 & 57.14 & 595.00 \\
$8 \% \leq M<10 \%$ & 0.00 & 0.00 & 50.00 & 930.00 & 33.33 & 930.00 \\
$M \geq 10 \%$ & - & - & - & - & - & - \\
\hline \hline
\end{tabular}

Time to maturity is divided into three classes. The class of short-term options contains all options maturing within 30 days. Similarly, the classes of medium-term and long-term options consist of all options with a time to maturity between 30 and 90 days and more than 90 days, respectively. The category containing long-term options has only 303 observations, compared to 3,391 short-term options and 6,935 medium-term options.

Considering the frequency of call \& put butterfly spreads violations by option moneyness, I do not find any consistent pattern of the frequency increasing for options moving away from at-the-money. The frequency of call \& put butterfly spreads deviations also does not seem to increase as the time to expiration increases. However, for an option maturing within 90 days, it seems that arbitrage opportunities in both strategies (LCSP and SCLP) generate more profits when options are farther from the money. For the LCSP strategy, short-term options with moneyness less than $2 \%$ generates the lowest mean profit of 610.75 baht, while short-term options with moneyness greater than or equal to $10 \%$ generates the highest mean profit of 2,644.00 baht. Turning to the SCLP strategy, short-term options with moneyness less than $2 \%$ generates the lowest mean profit of 567.70 baht, while short-term options with moneyness greater than or equal to $10 \%$ generates the highest mean profit of $1,378.26$ baht. I also do not observe any relationship between option moneyness and size of violations for long-term options. For options with moneyness less than $6 \%$, their arbitrage profits from both LCSP and SCLP strategies increase as time to maturity increases.

\section{CONCLUSION}

Thailand Futures Exchange started trading SET50 Index Options in 2007 but liquidity has been low. To boost liquidity, the SET50 Index Options contract has been readjusted to better fit the trading style of local investors since October 29, 2012. This research utilizes daily data from October 29, 2007 to December 30, 2016 to test market efficiency and investigate the effect of contract adjustment on market efficiency. The methodology is based on call \& put butterfly spreads, which combine both call and put options. For the whole sample, the results show that arbitrage opportunities occur much more frequently in the LCSP strategy than in the SCLP strategy. In many cases, the LCSP strategy generates more arbitrage profits than the SCLP strategy. In the absence of transaction costs, the percentage and size of violations in the LCSP (SCLP) strategy are greater after (before) change in contract specification. The difference in arbitrage profits before and after the contract adjustment is statistically significant at $5 \%$ level when using the LCSP strategy. In addition, for an option maturing within 90 days, most results show an increase in size of violations when options are farther from the money or have more time remaining to expiry. Taking the bid-ask spread into account, the percentage and the size of the violations decrease substantially over the whole sample. Therefore, our results support the efficiency of SET50 Index Options market before and after the modification of contract specification. I also observe an insignificant increase in both percentage and baht amount of violations after contract adjustment. Therefore, the results do not provide support for the argument that the SET50 
index options market efficiency improved after the contract adjustment.

\section{REFERENCES}

[1] G. Capelle-Blancard and M. Chaudhury, "Efficiency tests of the french index (CAC40) options markets," presented at the European Financial Management Association 2002 Annual Meetings, London, England, June 26-29, 2002.

[2] J. Lertburapa, "A test of put-call future parity in TFEX," presented at the 8th SEC Working Papers Forum, Bangkok, Thailand, September $16,2015$.

[3] W. Jongadsayakul, "A box spread test of the SET50 index options market efficiency: Evidence from the Thailand futures exchange," International Journal of Economics and Financial Issues, vol. 6, no. 4, pp. 1744-1749, 2016.

[4] W. Jongadsayakul, "Arbitrage opportunity in Thailand futures exchange: An empirical study of SET50 index options," ICE \& ISEC Proceedings, pp. 381-1-381-7, 2017.

[5] W. Jongadsayakul, "The internal efficiency test of SET50 index options market: Call options vs. put options," Applied Economics Journal, vol. 24, no. 2, pp. 1-16, 2017.

[6] A. Dixit, S. S. Yadav, and P. K. Jain, "Testing lower boundary conditions for index options using futures prices: Evidences from the indian options market," The Journal for Decision Makers, vol. 36, no. 1, pp. 15-31, 2011.

[7] A. Kamara and T. W. Miller, Jr., "Daily and intradaily tests of european put-call parity," Journal of Financial and Quantitative Analysis, vol. 30, no. 4, pp. 519-539, 1995.
[8] S. Li, "The arbitrage efficiency of the nikkei 225 options market: A put-call parity analysis," Monetary and Economic Studies, vol. 24, no. 2, pp. 33-54, 2006

[9] Z. Zhang and R. N. Lai, "Pricing efficiency and arbitrage: Hong Kong derivatives markets revisited," Applied Financial Economics, vol. 16, pp. 1185-1198, 2006.

[10] L. F. Ackert and Y. S. Tian, "Evidence on the efficiency of index options markets," Economic Review-Federal Reserve Bank of Atlanta, vol. 85, no. 1, pp. 40-52, 2000.

[11] L. F. Ackert and Y. S. Tian, "Efficiency in index options markets and trading in stock baskets," Journal of Banking \& Finance, vol. 25, no. 9 , pp. 1607-1634, 2001.

[12] A. G. Ronn and E. I. Ronn, "The box spread arbitrage conditions: Theory, tests, and investment strategies," Review of Financial Studies, vol. 2, no. 1, pp. 91-108, 1989.

[13] H. Stoll, "The relationship between put and call option prices," Journal of Finance, vol. 24, no. 5, pp. 801-824, 1969.

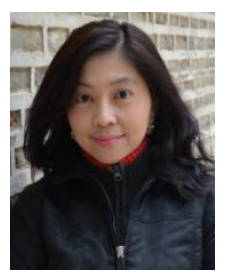

Woradee Jongadsayakul is an associate professor of economics at Kasetsart University, Bangkok, Thailand. She received her B.B.A. in finance from Chulalongkorn University (Bangkok, Thailand) in 1999, M.F. from Saint Louis University (Missouri, USA) in 2001, M.A. in economics from University of Colorado at Boulder (Colorado, USA) in 2003, and $\mathrm{Ph}$.D. in economics from University of Colorado at Boulder (Colorado, USA) in 2006. Her teaching and research interests are in business economics, financial risk management, and industrial organization. 